\title{
Growing Pains: The Transformative Journey from a Nascent to a Formal Not- For-Profit Venture
}

Avery C. Edenfield, $1 \square$

Phone 423-797-5791

Email avery.edenfield@usu.edu

URL http://techcomm.usu.edu/

Fredrik O. Andersson, 2

Phone (317) 2784898

Email fanders@iu.edu

URL http://www.spea.iupui.edu

1 Department of English, Utah State University, 3200 Old Main Hall, Logan, UT, 84322-3200 USA

2 School of Public and Environmental Affairs, Indiana University-Purdue University Indianapolis, $801 \mathrm{~W}$. Michigan Street BS 4066, Indianapolis, IN, 46202 USA

\section{Abstract}

This article examines how a social venture transitions from nascent to formal status and argues that the transformation of the organization set in motion by establishing formal boundaries is a deeply profound one. Drawing from the nonprofit and social entrepreneurship literature on what prompts and energizes individuals to initiate new not-for-profit ventures, and linking it to a notion of revolutionary crisis as organizations emerge and develop, we seek to illuminate and explore the tension, and its consequences, between nonprofit entrepreneurs and the organization they create as the new venture transitions from nascent to formal. We do this by presenting the results from an in-depth case study examining the gestation and boundary-forming phases of Robert's Place Cooperative, a plucky start-up cooperative in a midsize Midwestern city. 
New nonprofit organizations do not emerge from nothing, nor is nonprofit organizational emergence a discrete event but rather a process that entails multiple activities. To comprehend the development of nonprofits, many scholars have found it useful to map the process of nonprofit evolution into a series of stages or phases (Hasenfeld and Schmid 1989; Simon 2001; Stevens 2008; Connolly 2006). Two common principal stages in understanding new nonprofit emergence are (1) the preventure or nascent stage and (2) the start-up stage. The nascent stage encompasses activities taking place before the nonprofit is formally established, whereas the start-up stage encompasses activities once the nonprofit has obtained formal status (Stevens 2008). Each stage is viewed as having a set of definitional characteristics affecting various functions and structures of the emerging nonprofit.

As noted by Haugh (2007), many stage models assume that organizations naturally and rather effortlessly develop and adapt to each stage. However, in this study, we posit the move between stages is far from graceful or painless. Specifically, the purpose of this article is to add to the literature on nonprofit emergence by examining the crossing when a nascent nonprofit venture transitions into a formal start-up. We believe greater attention to the transition process is important as it sensitizes us to the notion that proceeding from one stage to the next is not a mechanical process. Also, studying transitions is essential to begin to comprehend how an organization's identity, structures, operational norms etc. become imprinted onto new organizations (Bryant 2014). Whereas existing research tends to focus on either nascent or start-up nonprofits, relatively few scholars have focused on the bridging between the two stages.

This article draws on two strains of literature. First, it uses the organizational lifecycle literature to frame the early stages of nonprofit evolution. Specifically, we draw from Greiner's (1972/1998) model of evolution and revolutionary crisis in organizations to illuminate the tensions in transitioning from the nascent stage to the start-up stage. Though the life-cycle perspective offers an intuitive frame for thinking about nonprofit evolution, it is predominantly descriptive and lacks nuance in capturing the connections among key actors and structures in the transition process. To analyze the multitude of interactions in the emergence and transition of a new nonprofit, we therefore complement the life-cycle perspective with an actor- 
network perspective (Latour 1991). Developed in the social sciences, actor-network theory (or ANT) has become a potent method to account for durability and stability in a fluctuating system (Latour 1991/1992; Law 1992; Star 1991). ANT provides us with tools to understand a network in flux that relies (as all organizations do) on a myriad of human and nonhuman components (called "actors" in ANT) to make the fluctuating system durable.

Our data come from an in-depth case study examining the gestation and boundaryforming phases of Robert's Place Cooperative (the name of the organization has been changed), a plucky start-up cooperative in a midsize Midwestern city. This 2year ethnographic study, which penetrated multiple structures and networks as well as informal and formal "texts," generated detailed and thick data well suited to capture the early life-stages of a new nonprofit venture.

\section{Literature Review}

Scholars have long used metaphors as a device to depict and understand organizations, and a common metaphor is to perceive at organizations as if they were living organisms (Morgan 1986). One application of this biological metaphor focuses on how organizations, like living organisms, pass through different stages of development and undergo a series of transitions over its lifetime (Chandler 1962; Lippitt and Schmidt 1967). These so-called life-stage models have also been applied to nonprofit organizations and remain popular, in part due to their intuitive appeal, but also because they describe (and in some cases, prescribe) how nonprofits progress (Stevens 2008; Brothers and Sherman 2011). As discussed in the introduction, the two central stages in the emergence of a new nonprofit are the pre-venture or nascent stage and the start-up stage. Both stages will be discussed in more detail shortly. However, the goal of organizational life-stage theory is not just to identify the different stages but also to comprehend the critical junctures and forces engendering organization evolution. To capture the evolution from nascent to formal organization, and the tensions characterizing such a shift, we look to Greiner's (1972/1998) seminal stage model for how organizations evolve. Greiner's work has served as important basis and inspiration for many subsequent models, including life-stage models in the nonprofit organizational field (e.g., Stevens 2008).

\section{The Nonprofit Nascent Stage}

New nonprofits do not simply materialize out of thin air fully functional and ready to offer new services and programs, which means many undertakings in the 
gestation of a new nonprofit organization transpire before the new entity becomes a formal operational entity (Andersson 2017). In other words, new organizations begin in a pre-venture or nascent stage before entering a formal start-up stage. As noted by Haugh (2007, p 162), the pre-venture phase is when "[...] people, ideas, resources, and opportunities are in the process of being brought together while structures and systems have yet to be embedded." Stevens (2008) adds a nascent stage nonprofit is demarcated by an idea rather than defined programs or services, operates primarily on sweat equity, has no board of directors, and management is undertaken by a coalition of supporters to the mission of the emerging organization.

Because no formal organization yet exists, nascent stage inquiries tend to emphasize two critical features: the intentions/goals and the resource mobilization efforts of the originator(s) of the new nonprofit venture idea. Any founding effort is a demanding endeavor requiring emotional investment as well as persistence. Intentions and goals are thus keys to unveil what fuels the commitment to initiate and move forward during the nascent stage (Bess 1998; Stevens 2008; Renko 2013). Furthermore, during the nascent stage, the intentions and goals of the originator(s) are in fact the same as the goals of the organization. It is only after the organization has been given a boundary as a formal (separate) entity it can possess goals distinct from those of founding entrepreneurs (Katz and Gartner 1988). These early intentions also become an essential part of the founding legacy of the new organization, a legacy that become imprinted and then persist as the organization evolves. Previous research has indeed illuminated how the intimate shared history of the founding team substantially influences the emergence and shaping of the organization's initial identity, values, and shared goals (Steier et al. 2004). The nascent nonprofit stage is also characterized by efforts to mobilize various types of resources (Hasenfeld and Schmid 1989; Bess 1998; Stevens 2008; Haugh 2007). Without the investments of others (funding, time, competence etc.), the nascent entity is left highly vulnerable and likely to fail (Stevens 2008). Nonprofit entrepreneurs are indeed aware of the need for such investments, and subsequently spends much time and effort during the nascent stage to mobilize start-up resources (Hasenfeld and Schmid 1989). As noted by Haugh (2007, p. 175), the mobilization efforts during the nascent stage are vital because these efforts ultimately shape the "tailor-made network" of stakeholders that will continue to evolve the fledgling nonprofit.

\section{The Nonprofit Start-Up Stage}


Whereas the nascent stage is "generally informal and unsystematic" (Hasenfeld and Schmid 1989, p. 247), and "little planning and coordination on a scale involving group members occurs" (Bess 1998, p. 49), the start-up stage looks very different. For example, according to Stevens (2008), a formal start-up stage nonprofit has developed some basic administrative and financial systems, a board of director has been installed, at least one distinct program/service has emerged, and work roles are being defined and designated (which often involves hiring staff). What happens when a nascent entity transforms into a formal venture is a need for structures and systems in response to several basic "how"-questions: how should the new organization be governed, how should it be managed, how can the organization best allocate its resources, how should the programs/services be designed and implemented, and so on (Stevens 2008). Hence, the transformation set in motion by establishing formal boundaries is a deeply profound one as it distinguishes the nonprofit entrepreneur-as-organization from the nonprofit entrepreneur-as-worker. Put differently, as boundaries conjoin it becomes possible for the new nonprofit to take coordinated action, but it now also distinguishes "[...] work done as an organization member (i.e., inside the boundary conditions) from work done as an individual (i.e., work done outside the boundary conditions)" (Katz and Gartner 1988 , p. 432). Boundaries limit the agency of the individual nonprofit entrepreneur(s), and create demands for structures and procedures among external and internal stakeholders.

\section{Stage Transition and the Greiner Model}

The transition from nascent to formal nonprofit signifies a major test and inflection point for the nonprofit entrepreneur(s) vis-à-vis the organization. This test is substantial, not because establishing formal organizational boundaries (e.g., incorporating the organization, filing for tax exempt status, forming a board of directors, establishing bylaws) is an especially complicated or expensive endeavor, but because boundaries can generate significant tensions and crisis when they clash with the original intentions that led the nonprofit entrepreneur(s) to undertake the entrepreneurial initiative in the first place (Renko 2013). For example, nascent stage imprinting can serve as a powerful source for resistance to change and adaptation, which may hamper the evolution of governance and leadership in the new organization as well as "[...] become a constraint on employees' initiative and flexibility” (Bryant 2014, p. 1084).

It is vital to point out the transition from nascent to start-up venture is not an automatic or assured process as evidenced by the fact that many attempts to found 
new organizations never progress beyond the nascent phase. As Renko (2013, p. 1045) remarks: "[t]he start-up process of a new venture is precarious: most entrepreneurial activities end in "near-misses," that is, organizations that die while emerging." Nor is it a matter of age. While transitions in living organisms (e.g., humans) can be connected to specific ages, organizational transitions are not age dependent (Stevens 2008). So, what initiates the transition from pre-venture nonprofit to nonprofit start-up? One life-cycle model providing insights into why stage transitions occurs is Greiner's (1972/1998) model of organizational development. What makes this model particularly useful is its focus on the interconnectedness that exists between various stages, and how the evolution of the organization is first and foremost determined by past experiences and events rather than what lies ahead, i.e., the effects of imprinting taking place in the preceding stage. Greiner (1972/1998, p. 58) depicts this reciprocal action in terms of evolution and revolution, stressing how the undertakings that characterize and shape one stage (e.g., the nascent stage) is also what "sow the seeds" of the decay of that stage and induces the revolution: "[m]anagers therefore experience the irony of seeing a major solution in one period become a major problem in a later period."

An essential element of the model is that stage transitions are generated by crisis stemming from the oscillation between forces for centralization and forces for decentralization. Here, we will only discuss the first two stages, and the crisis prompting the transition between these two early stages. The initial stage of an organization is labeled the stage of creativity, which centers on the founders and describe their repeated, yet informal, communication, high energy in attempting to progress the new organization, modest rewards for hard work, and a typically as disdain for management activities. This depiction aligns well with the notion of nascent activities.

Greiner (1972/1998) views the creative stage as being driven by individualistic undertakings, and the emerging organization tends to be reactive rather than strategic in its interaction with the external operating environment. But the selfdirected and decentralized nature of the creative stage can create tensions when the new organization seeks to engage in more purposeful collective action. Ultimately, the need to pull together is what brings forward the first revolution, the crisis of leadership, where the originators of the emerging venture (p. 60):

[...] find themselves burdened with unwanted management responsibilities. They long for the "good old days" and try to act as they did in the past. Conflicts among harried leaders emerge and 
grow more intense. At this point, a crisis of leadership occurs, which is the onset of the first revolution. Who will lead the company out of confusion and solve the managerial problem confronting it. [...] But finding that manager is easier said than done. The founders often resist stepping aside, even though they are probably temperamentally unsuited to the job.

Unless a new organization can resolve the crisis, it will not be able to transition to the subsequent stage - the stage of direction. According to Greiner (1972/1998, p. 60 ), the stage of direction is when the organization obtains "a functional organizational structure," systems and policies are introduced and adopted, increased specialization, internal and external communication is formalized and increasingly impersonal, and the "hierarchy of titles and positions grow." Again, this depiction corresponds closely to the formal start-up stage. Greiner notes this evolutionary period is not just more oriented toward a directive top-management style but also more efficiency oriented.

Though the Greiner model offers a compelling depiction of the early stages of organizational emergence and depicts the mechanism for stage transition, it has little to say about how to capture and analyze the transition between stages. The descriptive elements offer useful cues, yet to illuminate the shift from nascent to start-up nonprofit one must begin to consider more specific processes and relationships that join individuals, groups, and the organization. Hence, what is needed is a network perspective. As commented by Larson and Star (1993, p. 6), a networks perspective is well suited for capturing (emergent) organizing efforts, explicitly looks at linkages and exchanges among units, and recognizes the dynamic evolving nature of exchange, "which allows for greater insights into the sources of stability and flexibility in collective activities."

\section{The Actor-Network Approach}

For this research, a network theory provides us with a lens for understanding not only the connections between individuals involved in the formation and evolution of Robert's Place but also to obtain a broader picture than what a singular focus on human agency and action could provide. To better capture and comprehend the transition, and to provide granularity to our analysis of Robert's Place, we drew from ANT, a system-analysis approach most often associated with Latour (1992/1992) and Law (1992) and the social sciences, but carried over in the last decades into many other fields, like organizational studies (Alcadipani and Hassard 2010; Durepos and Mills 2012), nonprofit administration (Andersson and Edenfield 
2015), education (Fenwick 2010; Fenwick and Edwards 2012), technical communication (Potts 2010; Spinuzzi 2007), medical sociology (Greenhalgh and Stones 2010), urban studies (Farías and Bender 2012), and even accounting (Justesen and Mouritsen 2011), to name a few. For ANT, systems are made up of actors, and these systems crucially include the "nonhumans actors" who play an important role in affecting the system (Latour 1992, p. 177). According to Potts (2010), these actors can include texts, "cell phones, blogs, people, and so forththat have the ability to act and do act within the network" (pp. 285-286). The inclusion of nonhumans in its analysis is a defining characteristic of ANT, a strategy that researchers can use to "challenge assumptions about social context of machines," understood to be a part of our daily experience, who co-constitute our lives and work (Latour 1992, p. 153). ANT is a useful approach for studying an organization's transition from nascent to formal stage for two reasons. First, it provides the means to trace changes in the structures, especially in accounting for the unique horizontal arrangement of power and control at Robert's Place. Second, it allows us to capture the complexity of an informal organization, especially the nascent stage. Importantly, it allows us to not only study informal entities but also to capture the complexity of these early stages and to take a much wider perspective.

In addition to the above benefits, deploying an ANT-informed analysis also provides us a unique lens for looking at a key mechanism in the formation of Robert's Place, namely the texts they wrote. There is some precedent for appropriating ANT to examine communication systems, including rhetorical inquiry, in order to consider the roles of texts: not only as nonhuman actors, but also the social effects of those texts (Spinuzzi 2007). For that, ANT is hybridized with rhetorical analysis, i.e., a close examination of the connection between persuasion and language (Keith and Lundberg 2008, p. 3). One example of a hybridized ANT analysis is Spinuzzi's (2007) study of telecommunication networks in which he coupled ANT with rhetorical analysis for an approach that is both "political and rhetorical," looking at the "political/rhetorical movements of complex heterogeneous networks" (50-51). Aligned with Spinuzzi's (2007) project, we combine ANT and rhetorical analysis for an examination that considers both the content of organizational documents and the connections between those documents and members within the actor network of Robert' Place. For example, an employee handbook would be significant not only through its connection with other actors within the network but also through the rhetorical effects of the texts itself. A hybridized ANT approach would find this employee handbook significant not only 
by its functions and implications as a handbook, but also the language, visuals, organization, and, most importantly, social consequences of that handbook.

\section{Methodology}

The setting for this research is Robert's Place, a communally run, cooperatively owned bar in a blue-collar neighborhood in a large Midwestern city. While the cooperative model has been around for centuries, at the time of writing it was only a handful of cooperatively owned bars in the USA. Because cooperatively owned pubs are less common than other cooperatives, there are few existing structures from which to develop up the business. In other words, the founders of Robert's Place sought to be innovators rather than replicators. Thus, most of Robert's Place practices are emergent, conditional, and heavily reliant on its founders, seasoned cooperative developers in their own right.

Robert's Place was composed of two components. First, member-owners bought into the cooperative by paying annual dues. Second, a Workers Collective and Board of Directors managed the organization together. Running daily operations, the Workers Collective was an amalgamation of positions such as bouncers, bartenders, coordinators, and a finance team. The Board of Directors was elected in a majority vote to oversee the pub and to supervise the Workers Collective (Bylaws 2011). Though the Board carried legal responsibility, in practice, the bar operated through shared management between the Workers Collective and the Board. For example, the Board encouraged employees to run for open seats and several employees attend Board meetings to give input. In addition to creating jobs and hosting community organizing events, one organizational goal was to put a percentage of profits back into cooperative development in the neighborhood, starting with the creation of an apex organization, the Neighborhood Cooperative Alliance (NCA) (the name has been changed). The NCA administered the use of the funds for education, start-ups, technical support, and capacity building for the neighborhood cooperatives. Supporting cooperative development of the neighborhood was identified by interviewees as a core organizational goal (Steve, Patty).

Using ANT, we sought to document the different properties of the nascent stage, start-up stage, and the transition period. As noted by Larson and Starr (1993, p. 12), network models can be "operationalized through the use of intensive interviews and ethnographic study." The data used for this case are drawn from an ethnographic examination of Robert's Place as well as from various Robert's Place participant 
artifacts. One author was employed by Robert's Place from 2012 to 2015, and in 2013 was elected by members to serve on the Board of Directors for a 3-year term, ending in May 2016. The author is not currently and never has been in any supervisory relationship with any Board members or employees. In an act of reciprocity, Robert's Place benefited from this project by receiving recommendation reports on improving communication and other relevant findings. The closeness of the author allowed for an exhaustive examination of statements regarding decisionmaking, accountability, and transparency, as well as information exchanges via various communications tools occurring within Robert's Place. To understand the relationships between internal dynamics and the texts Robert's Place created and deployed, various artifacts were collected from Robert's Place participants, including the founding team: project management documentation, emails, text messages, training documents, regulations, handbooks, and other texts relevant to inventory, finances, and events. We also analyzed a variety of artifacts generated by participants. To better understand motivations, narratives, and actions at Robert's Place, $5 \mathrm{~h}$-long, in-person interviews were conducted with founders, past and present staff, and board members. Interviews were recorded and examined in conjunction with other documentation. Data collection lasted approximately 8 months. The process of analyzing and disseminating findings took approximately 18 months.

With the fieldwork and data collection completed, the researcher established a requisite distance in order to analyze of the data that had been collected. One of the goals of this analytical stage was to conduct one of the first in-depth study of organizational change within a cooperative and take make moves toward developing a theory of such change. Although only one author was involved in data collection, both authors came together to interpret and discuss the data resulting in a highly productive stage of dialogue and reanalysis of data. To illustrate the progression of Robert's Place from the nascent to formal stage, key episodes and texts in the evolution of the organization were selected for this article. Excerpts from the researcher-initiated interviews, excerpts from the field researcher's notes, and texts from other artifacts are all reproduced in the findings section. As with many other published ethnographies, these excerpts represent only a distillation of a much wider and richer empirical material.

\section{The Evolution of Robert's Place}

During our study, Robert's Place underwent significant changes because of conflicts and divisions at the heart of the organization. The timeline of the evolution, which 
we analyze in depth below, can be traced as follows.

- Nascent stage (Mobilizing effort, early organizational structures).

- Instability $\rightarrow$ Crisis and Conflict $\rightarrow$ Change.

- Formal stage: new normal.

Each transition is driven by messy, complex network of organizational goals, individual efforts, material necessities, and a range of artifacts deployed for various ends.

\section{Intentions and Mobilization Effort}

Robert's Place originated as an idea among individuals motivated to start a cooperative - and to build a self-sustaining business for the neighborhood - by utilizing grassroots organizing strategies. The founders were not experienced entrepreneurs, rather early accounts reveal many of the founders as political activists and community organizers. Their experience in organizing people for a cause informed the earliest strategies for developing Robert's Place. That is, instead than opening the business with established methods of feasibility studies, market research, and start-up funds, the earliest writings reflected a do-it-yourself (DIY) ethos, with methods including bootstrapping, knocking on doors, word-of-mouth recruitment, and personal outreach.

These initial strategies demonstrate that people in the founding network shared many civic concerns and were convinced of the value of a new cooperative for the neighborhood. One of the founders, Steve (please note that all names used in this article have been changed), declared that from the start, "it was more than just opening up a bar," but was instead motivated by a "broader goal of using that to then fund other initiatives, organizations, projects..." Building a socially conscious organization was a significant motivation for the founders, whose accounts demonstrate they believed they were creating an organization that was firmly committed to doing good works for the public and encouraging open and democratic participation.

The desire to open a cooperative embedded in and responsible to the neighborhood guided their every decision. Initially, the founders considered many types of businesses, including a bakery. 
Yet, the desires for a fast turnover and the expenditure of organizing energy motivated the decision to open as a bar. Accounts conflict as to who and how it was first suggested, but interviewees agreed that once the idea of a bar was proposed and framed as a "fast way to make a lot of money," energy began to coalesce. In interviews, founders agreed that the reason the idea of a cooperative bar gained momentum was because it could start with comparatively little overhead beyond rent, licenses, and initial inventory-all comparatively inexpensive in this particular city-whereas a bakery would require substantial start-up money for supplies and "could possibly take years to turn a profit (Will)."

The group of friends used diverse strategies to construct the organization and to activate community support by enrolling other neighbors into the new network. That is, rather than enrolling professionals and experts, the founders used community organization methods to build energy, raise money and gather participants, publicly marketing their idea that people without expertise could actualize an organization to their own advantage. For example, Lucy coincidently overheard a conversation at another cooperative where she was employed.

I was working [and] (Sophia) was talking with someone else who was in the cafe and then she was like, oh yeah we are starting to talk about opening a co-op bar...I thought it sounded interesting and was there to overhear the conversation.

Notably, she was not asked about her skill set or access to capital. Rather, it Lucy's proximity to and familiarity with cooperatives - that is, her existing position in the network of the neighborhood - positioned her as a candidate for participation in the new venture. Likewise, Levi and his partner were invited because of they too were in proximity to the network, living close to a business owned by one of the founders.

\section{Early Structure of Robert's Place and Goal Conflict}

While on the surface the founding group may have appeared homogenous, divisions on how to structure and to manage the organization were present from the beginning. Interviews with founders reveal at least two visions of the structure. Analysis shows that having a bifurcated and contradictory philosophy at the origin of Robert's Place became inscribed into the documentation they produced as they built the business together, creating a legacy for those to come. 
The first philosophy on structure derives from the do-it-yourself (DIY) culture of the neighborhood, an anarchist philosophy skeptical of expertise or administrative oversight. When questioned why more intentional supervisory mechanisms were not put in place or why expertise was not sought at the beginning of the organization, Patty attributed it to the ethos of community organizing, punk music, basement shows, zines, anti-civilization anarchism, and anti-consumerist activism.

The point of anything is to do it. You don't need to ask permission to do things; you don't need necessarily to have any expertise.[...] Coming out of that sort of cultural space and going into "How are we going to actualize a democratic economy? What does that look like? Do we need experts? Hell no we don't'. That's the attitude.

Other founders' accounts resonated with an ethos tied to anarchist commitments, an ideology that holds as its moral center a steadfast belief in individual autonomy, and in an organizational setting, self-management. As this ethic was incommensurate with conventional management strategies, we refer to it as selfmanagement for shorthand.

We also identified a second contradictory vision was held by others who had community mobilizing and/or cooperative experience. For example, Robert had experience in human resources, and Levi spent time as a bookkeeper. Those who held this position were responsible for "building process" (Levi; Robert), i.e. creating various texts that were intended to ensure transparency, instituting a grievance process, and creating internal control such as procedural notes, organization charts, governance calendars and other texts. Because they tended to focus on building process, we refer to this party as process-oriented.

Despite these philosophical divisions and high tension, the new group had to create documentation to open the business and legitimize it with state and local agencies. Rather than work to reconcile divergences, for expediency these divergences were "written around" by avoiding contentious policies and language, and only addressing content both positions could agree on. One result of this necessity of writing around their divergences is ambiguous documentation. This "strategic ambiguity" (Eisenberg 1984) in early texts created a looser organization with fewer policies and procedures, leading to instability in the earliest structure, with contradiction and conflict at its core. 
One clear example of this "writing around" is a document created via an affinity mapping activity at an organizing meeting. Clusters of ideas were transcribed into a "manifesto," an early organizing document key to early group cohesion and conflict resolution (Steve, Patty). While the manifesto symbolized a compromise between competing visions, it also reified tensions by not consolidating a unitary vision. For example, the title indicates the authors believed the organization they were building was radical, yet the contents show a rather mundane organizational text. This contradiction exemplifies the tension between the two visions: an efficient activist organization for some, and a DIY anarchist project for others. Importantly, notably missing from the fundamental framing document are key oversight mechanisms, disciplinary protocols, and other policies.

The manifesto mediated between the self-management and process-oriented philosophies. One example of this work is that the manifesto established the Workers Collective. The founders agreed that installing a distinct employee collective fulfilled the bylaw value-statement of "collective worker management" (Steve; Levi). Like the manifesto that instantiated it, the Workers Collective itself embodied the tense compromise between two visions of governance: a collectively managed workplace with some documented procedures and boundaries.

As the employee division of Robert's Place, the Workers Collective developed to include all staff. When the bar was founded people, initially volunteers operated the bar. Over time, volunteer positions transitioned into paid positions (Levi; Steve) and these roles were transcribed into "Job Descriptions \& division of labor for the Workers' Collective." Roles were filled by individuals who had been volunteering for some time. Only people with prior experience in bookkeeping or bar management filled the finance and managerial roles (Levi).

Significantly, the Workers Collective came into existence in part due to the mediation work by key texts like the manifesto, created in partnership by multiple people with competing visions and motivations. A close examination of these texts unveiled the responsibilities - and crucially, the shortcomings - of the Workers Collective to the Board of Directors and vice versa. For example, one text that instituted key positions within the Workers Collective is the board manual. According to the manual, the Workers Collective consisted of bartenders and four "auxiliary positions: events, inventory, finance, and a pseudo-manager, the bar coordinator ("Workers Collective Intro to New Hires"). Together, these four positions were intended to fill the role of a general manager and encompass all necessary managerial responsibilities. In line with their commitment to collective 
management, no one individual had unrecallable authority over another. Though the bar coordinator position was always intended in part to act as leadership, because of the tensions between the philosophies, people were reluctant to adopt conventional management terms in writing. The position of bar coordinator may have been vital to efficient operations, but an employee collective with a lead or pseudo-manager introduced a contradiction. Despite their work to veil the managerial position, because of tensions between founders, the bar coordinator role remained ambiguous, yet empowered by the Board to act. Forcing the bar coordinator between the Scylla and Charybdis ultimately established a norm of hybridity between horizontal and vertical structures, setting a precedent that would eventually be a turning point for the organization. Already, the network-made of documents like manifesto, job descriptions, bar coordinator and various positions-was beginning to experience instability.

\section{Instability in the Early Organization}

Early in its existence, the bar became unstable. One significant example of this instability is the rift between paid and unpaid employees, a conflict grounded in the tension between process and self-management philosophies identified above. Like many small organizations, Robert's Place initially operated through volunteer labor. The introduction of profit motive and paid labor was a watershed moment for the new organization. As people began to rely more and more on the material reality of the bar, labor became a source of deep conflict. As volunteers, the founders initially sacrificed material reward to open the bar without the overhead of paying employees, but quickly they ran into accounting trouble (Levi). Working collaboratively, they introduced a wage system, and this system unveiled the conflict between actors who earned a wage and those who decided on the wage (though some individuals fell into both categories). Once the bar became more polarized between directors and employees, the rift deepened (Levi).

As this example shows, unlike a conventional business where, at an impasse, an executive would default as the decision maker, at Robert's Place, texts and agreements bound the organization together. An ANT analysis shows that organizational documents like the manifesto, bylaws, codes of conduct, and other co-created texts enrolled individual founders into the network to coordinate action. Yet, rhetorical analysis of the texts they created shows that because of ambiguity, these texts failed to address deep contradictions and tensions they embodied. For example, while the bar coordinator was seen as a "catch-all" position, the document failed to specify the boundaries of auxiliary positions. If the inventory coordinator 
failed to complete her assigned tasks, the bar coordinator may be expected to complete those duties (though this expectation was not clearly delineated in a document, nor consequences for failing to do so). Additionally, though a wage system was introduced, the rift between the producers of the product and oversight of production was not addressed clearly in any text. Because of disagreement, processes outlining wage review, pay increase, or performance oversights were not built into the documented structure of the business. Already, the story was beginning to fray around the edges.

\section{Crisis and New Normal}

Robert's Place's later instability is linked to its origin. The evolution from the nascent to formal phase brought to the surface the deep-seated rifts between two positions of governance. The desire to start an organization - one that could bring jobs into the community, give progressive activists a meeting place, and fund new cooperatives - was not enough in itself to create a stable, coherent organization. The need to create ambiguous documentation only served to delay the rift, but did little to remedy it. Though documents necessary for operations were created through compromise, the ideology of self-management resisted bureaucratic implementation. While the entrepreneurs' desires to create a space of autonomy and freedom served as motivation to open Robert's Place initially, as the manifesto and the wage-system rifts illustrate, the philosophy was difficult to operationalize, i.e., developing a stable organization that could also provide nearly limitless individual autonomy. Because of the fiercely individualist nature of the ideology, the selfmanagement faction was unable to create "policy" for ensuring autonomy. The network that made up Robert's Place fractured as governance was pitted against autonomy.

Importantly, over time, the boundaries of what was to become Robert's Place began to coalesce around addressing this fracture. As will be discussed in the subsequent section, the separation between the desires of what Robert's Place ought to be (in the idealized head of the entrepreneurs) and what it has become (an organization with ambiguous and permeable structures and incoherent goals) generated a crisis. This crisis, in turn, resulted in an alteration in the overall structure and a new "normal" for the cooperative.

\section{Crisis and Conflict}

Several significant conflicts threatened the survival of Robert's Place that ultimately resulted in a crisis and shift in identity. By spring of 2014, the lack of 
formalized roles, responsibilities, or internal controls lead to an increasing reliance on the Bar Coordinator to fill in the gaps. This reliance on a singular individual rather than the collective lead to the re-emergence of the conflict between selfmanagement and process-oriented governance perspectives in an increasingly destabilized network.

Workers Collective experienced failure at the junctures in workflow and operations as indicated by four critical events. First, the acting bar coordinator reported missing money (Lucas). Second, the power company threatened disconnection because of missed payments (Lucas, "A Couple of Issues..."). Third, the rent was past due and the landlord was furious. Significantly, the Board was not aware of these missed payments until the property owner contacted them through email (Emily, "Re: A Couple of Issues...") Fourth, compounding the financial management problems, inventory was being mismanaged. The inventory system was not in communication with the financial systems, yet bar coordinator communicated with both independently, attempting to fill in the gaps of all the positions but, given the constraints of the job, in an ad hoc manner. The bar coordinator, who had many years of management experience, resolved to fill gaps in job descriptions and accountability. Lucas must either act unilaterally as manager - contrary to the self-management culture of the bar-or knowingly allow failure. The situation quickly became critical as the bar lost money. On the edge of insolvency, employees were barely able to pay bills, including paychecks. In a demonstration of their emotional investment in their organizational goals, employees offered to work unpaid until the situation was resolved, an offer the Board refused.

\section{Change}

Frustrations boiled over the impending threat to the business (Board of Directors, 2014 April 12; Special Finance Meeting, 2014 April 6). Meeting notes reflect their deep anxiety (Board of Directors, 2014 April 12). Sensing the threat to the existence of Robert's Place, the Board of Directors instituted a series of changes, exerting a rare act of top-down authority upon the Workers Collective, temporarily suspending absolute collectivism and participatory management. This act ultimately unveiled the schism that had been present since its founding; the fracture was revealed.

To reconcile the network, the Board instituted a series of unilateral changes that altered the structure of Robert's Place. With the help and consent of the Workers Collective, the Board terminated all finance, inventory, and bar coordinator 
positions and consolidated them into two co-managers: one position focused on customer service, inventory, bartender training, and other "front end" needs, and a position focused on financial management (Board of Directors, 2014 April 12). In a departure from the self-management ideology, these two positions had nearly unilateral control. Both positions quickly moved to codify rules and expectations for employees, to create an employee handbook and to formalize training, oversight, and review, enrolling new documents into the network. When asked about the problem with asymmetrical power relations between a manager and the Workers Collective, the notes on that day recorded Will's response: "Workers Collective has no shortage of great goals and great ideas, but where we need the GMs is to enforce these. Workers collective decides the what, and the GMs decide the how" (Will). This response points toward a recognition that self-management had in part failed. That is, before the crisis the prevailing philosophy of management was free-form, open, and dynamic; after the crisis, Robert's Place moved toward bureaucratization and centralization, a rejection of self-management in favor of process.

Organizational narratives were altered to support the network changes and to create strong connections between the actors involved. The stories Robert's Place told about itself shifted to support a process perspective. One example of how this change was narrated is in the bylaws. Robert's Place's bylaws came to be interpreted in service of the reorganization, made visible through their internal narrative via meetings and email. To support the new network, the narrative shifted from a refusal to compromise on values of collective management to instead doing whatever necessary to keep the business open, even if it meant compromising on certain ideals. This shift was necessary to bring about stability as the network morphed to include new systems of oversight management.

\section{New Normal}

The new network of Robert's Place was significantly different from the original entrepreneurial vision of self-management and worker autonomy. Decision-making power was consolidated into the hands of two people who, in effect, had autonomy to act without input from the Workers Collective. This asymmetrical relationship exemplified a major change in governance. Whereas in the past, hiring decisions were made jointly between the human resources position and the Workers Collective, and approved by the Board of Directors. After the change, the new managers could unilaterally hire without approval or discussion from the Collective. Time management is another example of asymmetrical relations. 
Robert's House changed policy to direct bartenders to clock in and out. This form of "punch card" system allowed greater supervision of the employees' time. While the self-management culture had dominated Robert's Place prior to the crisis, afterward the focus shifted to support process, managerial oversight, and discipline. The authors of the revised structure understood that the ability for the co-managers to act with autonomy was integral to a functioning, streamlined, and efficient business. And they enacted change despite undermining their own philosophical beliefs.

Using actor-network theory of actors linking together over shifting contexts, we can see how Robert's Place demonstrates that new nonprofit organizations do not emerge from nothing, nor is nonprofit organizational emergence a discrete event but rather a process that entails multiple stages and activities. Robert's Place begins in the mind of founders as a social venture designed to serve the community, create jobs, and start new cooperatives. Its genesis and initial motivations are spurred on by a belief in self-management. As the network of Robert's Place transitioned from nascent to formal status, conflict between the vision of autonomy and organizational needs resulted in a crisis. This tension set the stage for a crisis where the nonprofit entrepreneurs of Robert's Place were forced to re-evaluate the organizational goals and structure of the emerging organization. This re-evaluation had substantial consequences for the original entrepreneurship team, yet the tension between entrepreneurs and the emerging structure was integral to the solvency, and thus survival, of the organization.

\section{Conclusion}

Through a close examination of the emergence and early evolution of one social venture, Robert's Place Cooperative, this article examined the transition from nascent to formal organizational status. Utilizing the lens of actor-network theory, we demonstrated how this evolution involved profound and complex changes, as the organization begins to distinguish itself and in a move from the nonprofit entrepreneur-as-organization to the nonprofit entrepreneur-as-worker. In our case study, we depict how the transition signified a major trial for the founding entrepreneurs vis-à-vis the organization as boundaries generate significant tensions when they clash with the original motivations and expectations that led the nonprofit entrepreneur(s) to undertake the entrepreneurial initiative in the first place. ANT provides us with a theory to illustrate these tensions and the transition by taking into account actors that might typically escape notice, actors that ultimately played a significant role like job descriptions, bylaws, and vision 
statements. It is important to note that this approach has obvious limitations. We consider our examination of Robert's Place an exploratory study, as such our objective has not been to test hypotheses but to show how an innovative network approach (ANT) can be used to uncover and analyze life-stage transitions. With respect to the empirical findings reported, one cannot generalize beyond the discrete entity analyzed for this study. Still, we want to end by highlighting two takeaways emanating from this study.

One key lesson the Robert's Place case teaches us is not to assume the path from early entrepreneurial intent to the creation of an operational social venture is a more or less mechanic or uncomplicated endeavor. The nonprofit sector is often perceived and presented as a place with low entry barriers where eager entrepreneurs can, rather effortlessly, create new organizations. However, we believe such a view grossly underestimates just how demanding it is to actually concretize the idea of a new social venture into something substantial. As observed by Aldrich and Martinez (2001, p. 41), “[...] a universal constant is that no matter how many entrepreneurs emerge, most do not succeed in creating lasting organizations." The question of how and why some nonprofit/social entrepreneurs succeed in creating new social ventures while others do not still remains underresearched. Specifically, few scholars have examined nascent (i.e., preorganization) nonprofit/social entrepreneurs, how and what they do, the problems they face, how they handle such problems, the number of nascent social ventures actually taking the step to a formal operational venture, and so on. Inquiries focusing on such questions would not only give us a better understanding of nonprofit entrepreneurship, but also help overcome the selection bias emanating from studying only those entrepreneurial efforts resulting in successfully established not-for-profit ventures.

A second observation is the centrality of capturing and reflecting on the process of new social venture emergence. New organizations do not simply appear fully functional but are the result of a gestation process. A key component of this process is imprinting, which we highlighted using Greiner's dynamic between evolutionary and revolutionary forces during the venture creation phase. What happened in the past is therefore vital to comprehend the trajectory and current events in any social venture start-up. Future research needs to pay closer attention, not just to what these imprinting factors are, but also to how the imprinting process works in social ventures. Finally, the Robert's Place case is an attempt to showcase the value of ethnographic and narrative approaches to paint a fuller and more nuanced picture of new social venture creation. Gestation is not an easy phenomenon to grasp, which 
speaks to the benefits of approaching this process from multiple angles with multiple methodological tools.

Ultimately, we hope to inspire more research into the social venture start-up dynamic. The creation of new social ventures is an important phenomenon. Each year a substantial number of individuals are engaged in various start-up efforts. New social ventures are likely to play a highly significant role for a multitude of reasons, e.g., by implementing new innovative programs and services, contributing to employment creation, and creating new social value. Yet, the process by which these new social ventures come about is both under-theorized and empirically under-studied, thus, suggesting much remain to be discovered and scrutinized.

\section{Compliance with Ethical Standards}

Conflict of interest Avery C. Edenfield was previously employed at the research site and was elected to serve on the Board of Directors for a 3-year term. Avery C. Edenfield presented research participants with recommendations and other relevant findings. Fredrik O. Andersson declared there is no conflict of interest.

\section{References}

Alcadipani, R., \& Hassard, J. (2010). Actor-network theory, organizations and critique: Towards a politics of organizing. Organization, 17(4), 419-435.

Aldrich, H. E., \& Martinez, M. A. (2001). Many are called, but few are chosen: An evolutionary perspective for the study of entrepreneurship. Entrepreneurship Theory and Practice, 25(4), 41-56.

Andersson, F. O. (2017). A new focus on nonprofit entrepreneurship research. Nonprofit Management and Leadership, (in press).

Andersson, F. O., \& Edenfield, A. C. (2015). Nonprofit governance and the power of things. Nonprofit Quarterly, Summer, 2015, 52-59.

Bess, G. (1998). A first stage organization life cycle study of six emerging nonprofit organizations in Los Angeles. Administration in Social Work, 22(4), $35-52$. 
Billeaux, M., Reynolds, A., Young-Hyman, T., \& Zayim, A. (2011). Worker cooperative case study: Isthmus Engineering \& Manufacturing. University of Wisconsin Center for Cooperatives Staff Paper \#9.

Brothers, J., \& Sherman, A. (2011). Building nonprofit capacity: A guide to managing change through organizational lifecycles. New York: Wiley.

Bryant, P. T. (2014). Imprinting by design: The microfoundations of entrepreneurial adaptation. Entrepreneurship Theory and Practice, 38(5), 10811102.

Chandler, A. (1962). Strategy and structure. Cambridge: MIT Press.

Connolly, P. (2006). Navigating the organizational lifecycle: A capacity-building guide for nonprofit leaders. Washington, DC: Boardsource.

Dollhopf, E. J., \& Scheitle, C. P. (2016). Explaining variations in the nonprofit founding process. Nonprofit Management and Leadership, 27(2), 261-272.

Durepos, G., \& Mills, A. J. (2012). Actor-network theory, ANTi-history and critical organizational historiography. Organization, 19(6), 703-721.

Farías, I., \& Bender, T. (Eds.). (2012). Urban assemblages: How actor-network theory changes urban studies. London: Routledge.

Fenwick, T. J. (2010). (un) Doing standards in education with actor-network theory. Journal of Education Policy, 25(2), 117-133.

Fenwick, T., \& Edwards, R. (Eds.). (2012). Researching education through actor-network theory. New York: Wiley.

Greenhalgh, T., \& Stones, R. (2010). Theorising big IT programmes in healthcare: Strong structuration theory meets actor-network theory. Social Science and Medicine, 70(9), 1285-1294.

Greiner, L. E. (1972/1998). Evolution and revolution as organizations grow. Harvard Business Review, 76(3), 55-68. 
Hasenfeld, Y., \& Schmid, H. (1989). The life cycle of human service organizations: An administrative perspective. Administration in Social Work, 13(3-4), 243-269.

Haugh, H. (2007). Community-led social venture creation. Entrepreneurship Theory and Practice, 31(2), 161-182.

Justesen, L., \& Mouritsen, J. (2011). Effects of actor-network theory in accounting research. Accounting, Auditing \& Accountability Journal, 24(2), 161-193.

Larson, A., \& Starr, J. A. (1993). A network model of organization formation. Entrepreneurship: Theory and Practice, 17(2), 5-16.

Latour, B. (1991). Technology is society made durable. In J. Law (Ed.), A sociology of monsters: Essays on power, technology, and domination. London: Rutledge.

Latour, B. (1992). Where are the missing masses? The sociology of a few mundane artifacts. In W. E. Bijke \& J. Law (Eds.), Shaping technology/building society: Studies in sociotechnical change. Cambridge: MIT Press.

Law, J. (1992). Notes on the theory of the actor-network: Ordering, strategy and heterogeneity. Systems Practice, 5, 379-393.

Lippitt, G. L., \& Schmidt, W. H. (1967). Crises in a developing organization. Harvard Business Review, 45, 102-112.

Katz, J., \& Gartner, W. B. (1988). Properties of emerging organizations. Academy of Management Review, 13(3), 429-441.

Keith, W. M., \& Lundberg, C. O. (2008). The essential guide to rhetoric. Martins, New York: Bedford/St.

Miller, C. R. (1984). Genre as social action. Quarterly Journal of Speech, 70, $151-167$.

Morgan, G. (1986). Images of organisation. Thousand Oaks: Sage. 
Potts, L. (2010). Using actor network theory to trace and improve multimodal communication design. Technical Communication Quarterly, 18, 281-301.

Renko, M. (2013). Early challenges of nascent social entrepreneurs. Entrepreneurship Theory and Practice, 37(5), 1045-1069.

Robert's Place. (2011). “[Redacted] cooperative bylaws”. Ratified March 2011.

Robert's Place. (2012). "Introduction to workers collective”. New employee orientation presentation. January, 2012.

Robert's Place. (2013a). "[Redacted] cooperative board manual”. Unpublished internal document.

Robert' Place. (2013b). "Job descriptions \& division of labor for the [Redacted] Workers' Collective”. Unpublished internal document.

Robert's Place. (2013c). Special meeting of the Board of the Directors. August 17, 2013.

Robert's Place. (2014a). “Divvyed job descriptions updated 4.26.14”. Unpublished internal document.

Schryer, C. (1994). The lab vs. the clinic: Sites of competing genres. In A. Freedman \& P. Medway (Eds.), Genre and the new rhetoric. London: Taylor.

Simon, J. S. (2001). Five life stages of nonprofit organizations: Where you are, where you're going, and what to expect when you get there. Saint Paul, MN: Fieldstone Alliance.

Spinuzzi, C. (2007). Who killed Rex? Tracing a message through three kinds of network. In M. Zachry \& C. Thrall (Eds.), Communicative practices in workplaces and the professions: Cultural perspectives on the regulation of discourse and organizations. Amityville: Baywood Press.

Star, S. L. (1991). Power, technologies, and the phenomenology of conventions: On being allergic to onions. In J. Law (Ed.), A sociology of monsters: Essays on power, technology, and domination. London: Rutledge. 
Steier, L. P., Chrisman, J. J., \& Chua, J. H. (2004). Entrepreneurial management and governance in family firms: An introduction. Entrepreneurship Theory and Practice, 28(4), 295-303.

Stevens, S. K. (2008). Nonprofit lifecycles: Stage-based wisdom for nonprofit capacity (2nd ed.). Long Lake, Minnesota: Stagewise Enterprises.

Winsor, D. A. (2003). Writing power: Communication in an engineering Center. Albany: SUNY UP.

Winsor, D. A. (2007). Using texts to manage continuity and change in an activity center. In M. Zachry \& C. Thrall (Eds.), Communicative practices in workplaces and the professions: Cultural perspectives on the regulation of discourse and organizations. Amityville: Baywood Press.

Zeuli, K. A., \& Cropp, R. (2004). Cooperatives: Principles and practices in the 21 st century. University of Wisconsin Extension Publication, A1457. University of Wisconsin Center for Cooperatives.

\section{Interviews}

"Levi". (2014, November). Face to face interview.

"Lucy". (2014, July). Face to face interview.

"Patty". (2014, July). Face to face interview.

"Robert". (2014, September). Face to face interview.

"Steve". (2014, June). Face to face interview. 